Research Article

\title{
Statistical Damage Constitutive Model for Cemented Sand considering the Residual Strength and Initial Compaction Phase
}

\author{
Cai Tan $\mathbb{D}^{1},{ }^{1}$ Ming-dao Yuan $\mathbb{D}^{1},{ }^{1}$ Yong-sheng Shi $\mathbb{D}^{,},{ }^{1}$ Bing-sheng Zhou $\mathbb{D}^{2},{ }^{2}$ and Hao Li $\mathbb{D}^{3}$ \\ ${ }^{1}$ Guangdong Research Institute of Water Resources and Hydropower, Guangzhou 510610, China \\ ${ }^{2}$ Key Laboratory of Ministry of Education for Geomechanics and Embankment Engineering, Hohai University, Nanjing, \\ Jiangsu 210098, China \\ ${ }^{3}$ State Key Laboratory of Hydraulics and Mountain River Engineering, College of Water Resource \& Hydropower Engineering, \\ Sichuan University, Chengdu 610065, China \\ Correspondence should be addressed to Cai Tan; sancytan@163.com
}

Received 9 July 2018; Revised 30 August 2018; Accepted 9 September 2018; Published 29 October 2018

Academic Editor: Castorina S. Vieira

Copyright ( 92018 Cai Tan et al. This is an open access article distributed under the Creative Commons Attribution License, which permits unrestricted use, distribution, and reproduction in any medium, provided the original work is properly cited.

\begin{abstract}
Based on continuum damage mechanics and the assumption of volume invariance, a damage constitutive model of cemented sand under triaxial stress was established while considering residual strength. Statistical theory was then introduced into this model. Assuming that the microunit strength of cemented sand obeys a Weibull random distribution, an expression of microunit strength based on the Mohr-Coulomb criterion was derived. Additionally, a damage evolution equation and a statistical damage constitutive model of cemented sand under triaxial stress were established. In order to consider the nonlinear deformation and volume change in the initial pore compaction stage, the critical point reflecting the completion of the initial compaction stage was determined. This was done by applying the volume invariance assumption to the linear portion of the stress and strain curve and performing a coordinate transformation. The nonlinearity of the initial compaction stage was fitted by a quadratic function. A triaxial compression test of cemented sand was then carried out to verify this proposed method. The results show that the calculated values by the damage constitutive model fit well with the actual experimental values and that the calculated results can reflect the stress softening, residual strength, and initial compaction characteristics of cemented sand, which shows the rationality and feasibility of the model.
\end{abstract}

\section{Introduction}

Sea dikes are an effective engineered sea defense, which have been widely used in coastal areas. As sand is readily available in these regions, many sea dikes were filled by sand [1-3]. Due to rapid erosion characteristics, there are many problems with sand-built sea dikes. In recent years, with the increasing investment in water conservancy construction, a large number of old sea dikes have been reinforced. Because clay material is lacking in coastal areas, sand has still been used as a major material in engineering the sea dike reinforcements. To prevent sand loss, a concrete board was built on the sea side as a protective face, and a layer of geotextile was placed between the sand and concrete surface.
This investigation shows that the degree of damage is very high due to sand loss, which caused the separation between the concrete slab and the sand, as shown in Figure 1 [4]. A small amount of cement can solidify sand effectively, which greatly reduces the sand loss and ensures the safety of the sea dike. Therefore, research on cemented sand materials is of great significance.

Scholars have been researching cemented sand since the 1970s, and great progress has been made in this field [5-7]. Trads et al. [8] carried out triaxial testing and DEM simulation on cemented sand. Their results show that density, confining pressure, and cement ratio are the three main factors that affect the mechanical properties. Consoli et al. [9-11] conducted a large number of mechanical tests on 


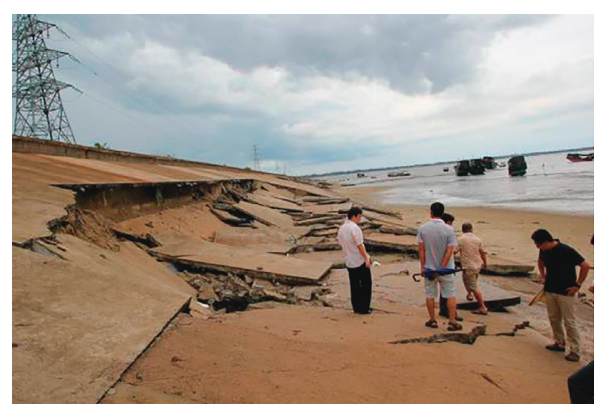

(a)

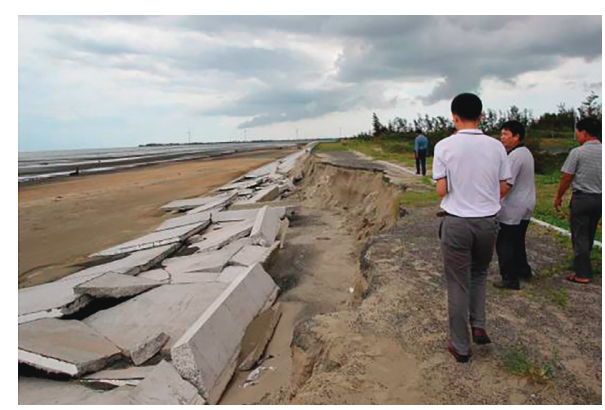

(b)

Figure 1: Sand embankment damage caused by sand loss (reproduced from Tan et al. [4]). (a) Panel breakage caused by sand loss. (b) Panel slipping caused by sand loss.

cemented sand, and an empirical expression of compressive strength based on curing time, porosity, and cement content was established. Wang et al. [12] carried out triaxial tests and quantitative chemical tests on cemented sand with different mixing ratios of calcium oxide and analyzed the effect of calcium oxide content on the physical and mechanical properties.

The constitutive model, which can describe the complete stress-strain process of cemented sand, is a key point in cemented sand research [13-15]. As a complex mixture with obvious nonuniformity, the mechanical mechanism of cemented sand is difficult to clarify and the constitutive model is difficult to establish. Macroscopic mechanical properties can be regarded as the average effect of many mesomechanical properties, assuming that the strength of the microelement in the cemented sand obeys the statistical distribution. The statistical damage constitutive model can describe the whole deformation process of cemented sand using a unified equation [16-19]. However, the statistical damage constitutive model is based on the hypothesis of Lemaitre strain equivalence, where the residual strength of the material is not considered [20]. Therefore, it is necessary to modify the statistical damage constitutive model to include residual strength.

Cemented sand contains a large number of pores, which cause obvious nonlinear deformation at the initial void compaction stage [21]. The constitutive model based on statistical damage theory cannot accurately reflect this phenomenon. Therefore, it is of great value to establish a constitutive model that can accurately describe the nonlinear process of nonlinear deformation. Wang et al. [22] artificially divided the typical stress-strain curve into two parts and established two separate constitutive models. In the microcracks closure phase, new factors were proposed to describe the effect of the change of porosity on the deformation behavior of rock. Cao et al. [23], based on a full discussion of the deformation mechanism of porous rocks and a combination of the methods for macroanalysis and microanalysis, established a deformation analysis model for porous rocks by abstracting porous rocks into two parts, rock skeletons and voids.

In this study, statistical theory was introduced by considering that the strength of the inner microelement obeys the statistic distribution. Using continuum damage mechanics, the total volume invariance hypothesis, and the Mohr-Coulomb criterion, the statistical damage constitutive model of cemented sand with residual strength was developed. Then, the critical point of the initial compaction stage was defined and the initial void compaction stage was fitted with a quadratic function. In addition, laboratory tests were carried out to verify the theoretical model.

\section{Statistical Damage Constitutive Model with Residual Strength Considered}

2.1. Damage Constitutive Model of Cemented Sand. According to the Lemaitre strain equivalence hypothesis [24], for the same material, the strain produced by the damaged part is equal to that of the undamaged part under effective stress. It can be written as

$$
\sigma=\sigma^{*}(1-D)
$$

where $\sigma$ is the macroscopic stress of the cemented sand microelement, $\sigma^{*}$ is the microscopic stress of the undamaged part, and $D$ is the damage factor.

The Lemaitre strain equivalence hypothesis has its limitations; for example, it considers the material to have lost its functional carrying capacity when completely damaged. However, the cemented sand triaxial compression test results showed that the damaged part of the material still has a certain bearing capacity. Therefore, a microelement stress model [24, 25], used to describe the residual bearing capacity of rock, was introduced, as shown in Figure 2.

According to the stress balance of the microelement of cemented sand, the following equation can be obtained:

$$
\sigma A=\sigma^{*} A_{1}+\sigma^{r} A_{2}
$$

where $\sigma^{r}$ is the damaged part which has a certain residual strength, $A$ is the total area of the microelement, $A_{1}$ is the area of the undamaged part, and the total damaged area is $A_{2}=A-A_{1}$, which can be rewritten as

$$
\sigma=\sigma^{*} \frac{A_{1}}{A}+\sigma^{r} \frac{A_{2}}{A} \text {. }
$$

The damage factor $D$ is defined as the ratio of the area of the damaged part of the cemented sand to the total area, that is, $D=A_{2} / A$. 


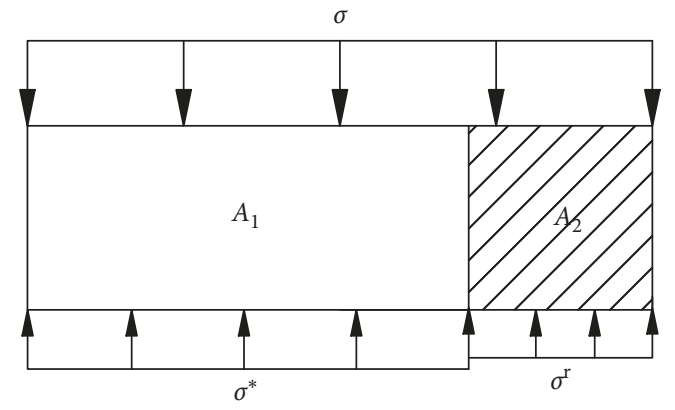

FIgURE 2: Stress model of cemented sand microelement.

Therefore, with residual strength considered, Formula (1) can be rewritten as

$$
\sigma=\sigma^{*}(1-D)+\sigma^{r} D .
$$

When the cemented sand is completely damaged, $D=1$; it still has a stable residual bearing capacity $\sigma^{r}$. Assuming that the damage of cemented sand is isotropic, we get

$$
\begin{aligned}
& \sigma_{1}=\sigma_{1}^{*}(1-D)+\sigma_{1}^{r} D, \\
& \sigma_{3}=\sigma_{3}^{*}(1-D)+\sigma_{3}^{r} D,
\end{aligned}
$$

where $\sigma_{1}$ is the major principal stress, $\sigma_{3}$ is the minor principal stress, $\sigma_{1}^{*}$ is the major principal stress of the undamaged part, $\sigma_{3}^{*}$ is the minor principal stress of the undamaged part, $\sigma_{1}^{r}$ is the major principal stress of the damaged part, and $\sigma_{3}^{r}$ is the minor principal stress of the damaged part.

Considering that the undamaged part is mixed with the damaged part randomly, according to the rule of deformation compatibility, the following equation can be obtained:

$$
\varepsilon=\varepsilon^{*}=\varepsilon^{r},
$$

where $\varepsilon$ is the macroscopic strain of the cemented sand microelement, $\varepsilon^{*}$ is the strain of the undamaged part, and $\varepsilon^{r}$ is the strain of the damaged part.

It is assumed that the elastic modulus of the undamaged part of cemented sand is equal to the nominal elastic modulus $E$ and obeys the generalized Hooke's law; thus, the following equation can be obtained:

$$
\left\{\begin{array}{l}
\sigma_{1}^{*}=E \varepsilon_{1}+\nu\left(\sigma_{2}^{*}+\sigma_{3}^{*}\right), \\
\sigma_{3}^{*}=E \varepsilon_{3}+\left(\nu \sigma_{1}^{*}+\sigma_{2}^{*}\right),
\end{array}\right.
$$

where $\sigma_{2}^{*}$ is the intermediate principal stress of the undamaged part, $v$ is Poisson's ratio, $\varepsilon_{1}$ is the strain in the direction of major principal stress, and $\varepsilon_{3}$ is the strain in the direction of minor principal stress.

For the triaxial test, $\sigma_{2}=\sigma_{3}$ and $\sigma_{2}^{*}=\sigma_{3}^{*}$, and it is assumed that the total volume in the loading process of cemented sand is constant. Therefore, the following equationcan be obtained [25]:

$$
\varepsilon_{v}=\left(1+\varepsilon_{1}\right)\left(1+\varepsilon_{2}\right)\left(1+\varepsilon_{3}\right)=1,
$$

where $\varepsilon_{v}$ is the volumetric strain and $\varepsilon_{2}$ is the strain in the direction of intermediate principal stress.
As $\varepsilon_{2}=\varepsilon_{3}$, it can be rewritten as

$$
\varepsilon_{3}=\varepsilon_{2}=\frac{1}{\sqrt{1+\varepsilon_{1}}-1} \text {. }
$$

Using Formula (8), the following equations can be obtained:

$$
\begin{aligned}
& \sigma_{3}^{*}=E \frac{\left(1 /\left(\sqrt{1+\varepsilon_{1}}+\nu \varepsilon_{1}-1\right)\right)}{1-\nu-2 \nu^{2}}, \\
& \sigma_{1}^{*}=E\left[\varepsilon_{1}+2 \nu \frac{\left(1 /\left(\sqrt{1+\varepsilon_{1}}+\nu \varepsilon_{1}-1\right)\right)}{1-\nu-2 \nu^{2}}\right] .
\end{aligned}
$$

When the cemented sand is completely damaged, according to the rule of Mohr-Coulomb, the following equation can be obtained:

$$
\sigma_{1}^{r}=\frac{\sigma_{3}^{r}\left(1+\sin \phi_{r}\right)+2 C_{r} \cos \phi_{r}}{1-\sin \phi_{r}},
$$

where $\phi_{r}$ is the residual internal friction angle and $C_{r}$ is the residual cohesive strength.

Using Equations (6) and (11), the following equation can be obtained:

$$
\sigma_{3}^{r} D=\sigma_{3}-E(1-D) \frac{\left(1 /\left(\sqrt{1+\varepsilon_{1}}+v \varepsilon_{1}-1\right)\right)}{1-v-2 v^{2}}
$$

The damage constitutive model of cemented sand can be obtained by simultaneously solving Equations (5), (12), and (14). It can be written as

$$
\begin{aligned}
\sigma_{1}= & E(1-D)\left[\varepsilon_{1}+\frac{\left(1 /\left(\sqrt{1+\varepsilon_{1}}+\nu \varepsilon_{1}-1\right)\right)}{1-\nu-2 v^{2}} \cdot\left(2 \nu-\frac{1+\sin \phi_{r}}{1-\sin \phi_{r}}\right)\right] \\
& +\frac{2 C_{r} \cos \phi_{r}}{1-\sin \phi_{r}} D+\frac{1+\sin \phi_{r}}{1-\sin \phi_{r}} \sigma_{3} .
\end{aligned}
$$

Assuming

$$
\left\{\begin{array}{l}
\alpha=1-\nu-2 \nu^{2} \\
\beta=\frac{1}{\sqrt{1+\varepsilon_{1}}+\nu \varepsilon_{1}-1} \\
\gamma=\frac{1+\sin \phi_{r}}{1-\sin \phi_{r}} \\
\lambda=\frac{2 C_{r} \cos \phi_{r}}{1-\sin \phi_{r}}
\end{array}\right.
$$

Equation (15) can be written as

$$
\sigma_{1}=E(1-D)\left[\varepsilon_{1}+\frac{\beta}{\alpha} \cdot(2 v-\gamma)\right]+\lambda D+\gamma \sigma_{3} .
$$

2.2. Damage Evolution Equation. Cemented sand is a mixed material with many randomly distributed defects. The strength of the cemented sand is affected by a large number 
of factors, including the mineral composition and particle size of sand, the cement properties, and the distribution of defects. Therefore, it can be considered that the microelement strength of cemented sand is also a random variable and obeys the law of statistical distribution. Assuming that the microelement strength of cemented sand obeys the Weibull distribution, the following equation can be obtained:

$$
\phi(F)=\frac{m}{F_{0}}\left(\frac{F}{F_{0}}\right)^{m-1} \exp \left[-\left(\frac{F}{F_{0}}\right)^{m}\right],
$$

where $F$ is the distribution variable of the Weibull distribution and $m$ and $F_{0}$ are the Weibull distribution parameters.

It can be assumed that the failure interface of cemented sand consists of parallel microelements of number $N$ and that the number of damaged microelements $n$ in any interval of $[F, F+d F]$ is $N \Phi(x) d x$ as the load increases. The damage factor $D$ can be written as

$$
D=\frac{n}{N}=\frac{\left(\int_{0}^{F} N \phi(x) d x\right)}{N}=\int_{0}^{F} \phi(x) d x=1-\exp \left[-\left(\frac{F}{F_{0}}\right)^{m}\right] \text {. }
$$

According to the Mohr-Coulomb criterion, the microstrength of cement soil is established and expressed by principal stress.

$$
F=\sigma_{1}^{*}(1-\sin \varphi)-\sigma_{3}^{*}(1+\sin \varphi)=2 c \cos \varphi,
$$

where $c$ is the cohesive force and $\varphi$ is the internal friction angle of the cemented sand. Plugging Equations (11) and (12) into this equation, the strength of cemented sand can be rewritten as follows:

$$
F=E\left[\varepsilon_{1}+2 \nu \cdot \frac{\beta}{\alpha}\right](1-\sin \phi)-E \cdot \frac{\beta}{\alpha}(1+\sin \phi) .
$$

2.3. Parametric Solution of Constitutive Model. By developing Equation (19), the following equation can be obtained:

$$
\ln [-\ln (1-D)]=m \ln F-m \ln F_{0} .
$$

By developing Equation (17), the following equation can be obtained:

$$
D=\frac{\sigma_{1}-\gamma \sigma_{3}-E\left[\varepsilon_{1}+\beta / \alpha \cdot(2 \nu-\gamma)\right]}{\lambda-E\left[\varepsilon_{1}+\beta / \alpha \cdot(2 \nu-\gamma)\right]},
$$

Assuming

$$
\left\{\begin{array}{l}
y=\ln [-\ln (1-D)] \\
x=\ln F \\
b=-m \ln F_{0}
\end{array}\right.
$$

Equation (22) can be rewritten as

$$
y=m x+b
$$

where the specific values of $m$ and $F_{0}$ can be obtained by linear fitting the test data.

\section{Statistical Damage Constitutive Model with Initial Compaction Phase Considered}

The model proposed above is based on the assumption that the total volume of cemented sand is constant. The triaxial compression test results indicate that the cemented sand was compacted in the initial phase. Combined with the results of Reference [22], the typical stress-strain curves in the initial compaction stage of cemented sand under uniaxial compressive load are shown in Figure 3.

As shown in Figure 3, $E$ is the elastic modulus of the cemented sand skeleton without pressure-tight void defects. The deformation of cemented sand in the initial compaction stage (curve $O Q$ ) is composed of the deformation of the skeleton and void. The stress-strain curve presents as a parabolic curve. When entering the linear deformation stage $Q P$, the void deformation caused by the gap closure is essentially completed. At point $\mathrm{P}$, the slope of the stressstrain curve clearly decreases, which indicates that the skeleton of cemented sand is damaged and the deformation of the void part is completed. As it is difficult to determine the position of point $Q$, it is advisable to use point $P$ as the completion point of the gap compression. When the linear $Q P$ segment is lengthened to intersect the $O \varepsilon$ axis, the intersection abscissa $\gamma_{0}$ is the compacted pore deformation of cemented sand. It is worth noting that the compaction pore is not a traditional pore but the uneven distribution of macroscopic fissures and voids. Therefore, it is only part of the traditional pore that is prone to deformation in low stress states.

The analysis of the stress-strain curve of cemented sand under uniaxial compression needs to be extended to the triaxial force condition. As the stress-strain curve obtained by triaxial loading $\left(\sigma_{2}=\sigma_{3}>0\right)$ represents the eccentric stress and axial strain, the stress and deformation of the $\sigma_{1}$ loaded to $\sigma_{3}$ are not included in the curve. Therefore, the test curve should be further modified and discussed.

For convenience of analysis, 3 reference coordinate systems were established as shown in Figure 4.

Coordinate system I: the origin point is $O_{1}$, which reflects the relationship between $\sigma_{2}-\sigma_{3}$ and the axial strain $\varepsilon_{1}$ of cemented sand.

Coordinate system II: the origin point is $\mathrm{O}_{2}$, which reflects the relationship between the cemented sand axial stress $\sigma_{1}^{\prime}$ and strain $\varepsilon_{1}^{\prime}$ with only skeleton deformation.

Coordinate system III: the origin point is $\mathrm{O}_{3}$, which reflects the relationship between the actual axial stress $\sigma_{1}$ of cemented sand and axial strain $\varepsilon_{1}^{\prime \prime}$. The axial strain $\varepsilon_{1}^{\prime \prime}$ includes the deformation of $\sigma_{1}$ loaded to $\sigma_{3}$.

As shown in Figure 4, when the linear segment $Q P$ was extended to intersect with the $O_{1} \varepsilon_{1}$ and $O_{3} \varepsilon_{1}^{\prime \prime}$ axes, the intersection abscissa were $\gamma_{0}$ and $\gamma_{\mathrm{c}}$, respectively. The axial deformation of the cement soil is $\varepsilon_{\mathrm{c}}$ when the axial force is increased from 0 to $\sigma_{3}$. The following equation can be obtained: 


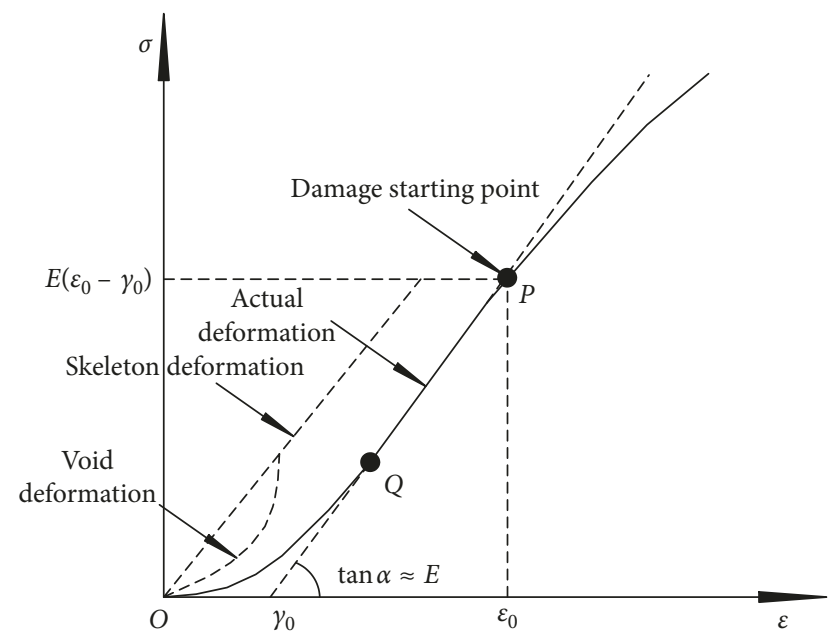

Figure 3: Characteristics of stress-strain curve at compaction stage $\left(\sigma_{2}=\sigma_{3}=0\right)$.

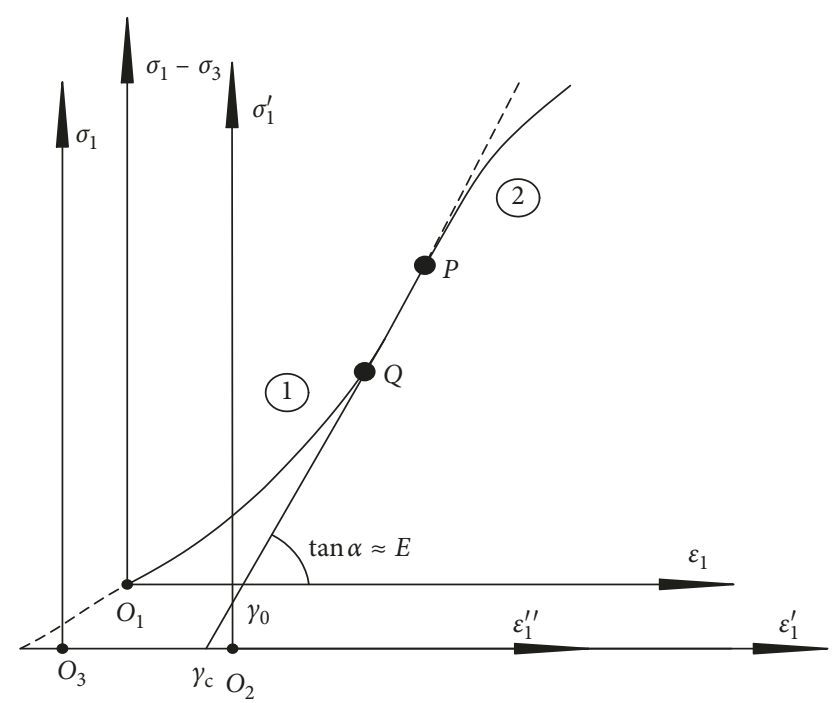

FIGURE 4: Characteristics of stress-strain curve at compaction stage $\left(\sigma_{2}=\sigma_{3}>0\right)$.

$$
k_{\mathrm{QP}}=\frac{\partial\left(\sigma_{1}-\sigma_{3}\right)}{\partial \varepsilon_{1}}=\frac{E}{\left(1-\gamma_{c}\right)} .
$$

As $\gamma_{c} \ll 1$, this can be rewritten as

$$
k_{\mathrm{QP}} \approx E \text {. }
$$

According to Figure 3 and Hooke's law, the relative position of the three reference systems is established. Figure 5 shows the transformation relationship between coordinates in the different coordinate systems. It can be seen from Figure 5 that, due to the effect of confining pressure $\sigma_{3}$, the ordinate intercept of reference systems II and III is not 0 . When $\sigma_{3}=0$, the stress-strain curve characteristic of cemented sand under uniaxial compression load is equivalent to Figure 3.

Therefore, the complete stress-strain curve of cemented sand, which obeys the morphological characteristics of Figure 3, is applicable to reference system III. The constitutive damage model of cemented sand based on the

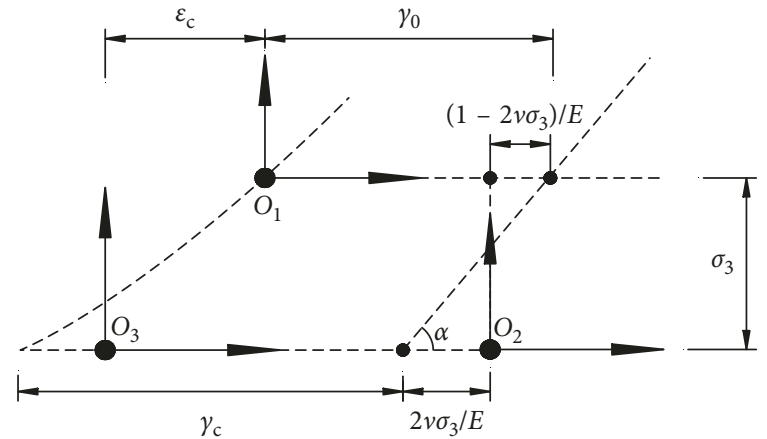

Figure 5: Positional relationships between 3 coordinate systems.

assumption of constant volume is only applicable to reference system II, and the experimental data are applicable to the reference system I. Therefore, in order to obtain data in the coordinate system of II for analysis, the following transformations were needed.

The test data in the coordinate system I can be set as $\left(\sigma_{1}=\sigma_{3}, \varepsilon\right)$, and the transformed data in the coordinate system II are $\left(\sigma_{1}^{\prime}, \varepsilon_{1}^{\prime}\right)$. According to Figures 4 and 5 , the following equation can be obtained:

$$
\left\{\begin{array}{l}
\sigma_{1}^{\prime}=\left(\sigma_{1}-\sigma_{3}\right)+\sigma_{3} \\
\varepsilon_{1}^{\prime}=\varepsilon_{1}+\varepsilon_{\mathrm{c}}-\left[\gamma_{0}+\varepsilon_{\mathrm{c}}-\frac{(1-2 \nu) \sigma_{3}}{E}\right], \\
=\varepsilon_{1}-\left[\gamma_{0}-\frac{(1-2 \nu) \sigma_{3}}{E}\right]
\end{array}\right.
$$

where $\gamma_{0}$ can be obtained by the method of geometric extension. The relationship between coordinate system II and coordinate system I is established. According to Formula (28), if the test data in the reference system II can be established, the data points in the coordinate system II can be solved according to the constitutive model in Section 2 and the theoretical value of the partial stress $\sigma_{1}-\sigma_{3}$ and axial strain $\varepsilon_{1}$ can be obtained by inverse transformation. However, the above method is only applicable to solving the theoretical values after critical point $(P)$, that is, curve (2) in the graph. For compaction stage (1), that is, the curved segment $O_{1} Q$ and the linear segment $Q P$, the quadratic function was proposed to express curve (2).

The form of curve (1) can be stated as

$$
\sigma=c \varepsilon^{2} \text {. }
$$

As the curve passes point $\mathrm{P}\left(\varepsilon_{0}, E\left(\varepsilon_{0}-\gamma_{0}\right)\right)$, it can be rewritten as

$$
E\left(\varepsilon_{0}-\gamma_{0}\right)=c \varepsilon_{0}^{2} \Longrightarrow c=\frac{E\left(\varepsilon_{0}-\gamma_{0}\right)}{\varepsilon_{0}^{2}},
$$

which then becomes

$$
\sigma=E\left(\varepsilon_{0}-\gamma_{0}\right) \cdot\left(\frac{\varepsilon}{\varepsilon_{0}}\right)^{2}, \quad \varepsilon \leq \varepsilon_{0} .
$$

If the point $Q$ is taken as the completion point of the compaction stage and a quadratic function is fitted to the 
curve segment $O_{1} Q$, the curve segment $O_{1} Q$ is tangent to $Q P$ at point $Q$. The coordinate of $Q$ point is $\left(\varepsilon_{q}, E\left(\varepsilon_{q}-\gamma_{0}\right)\right)$; therefore, the following equations can be obtained:

$$
\begin{gathered}
E\left(\varepsilon_{q}-\gamma_{0}\right)=c \varepsilon_{q}^{2} \Longrightarrow c=\frac{E\left(\varepsilon_{q}-\gamma_{0}\right)}{\varepsilon_{q}^{2}}, \\
\left.\frac{d \sigma}{d \varepsilon}\right|_{\substack{\varepsilon=\varepsilon_{q} \\
\sigma=E\left(\varepsilon_{q}-\gamma_{0}\right)}}=\frac{2 E\left(\varepsilon_{q}-\gamma_{0}\right)}{\varepsilon_{q}}=E .
\end{gathered}
$$

Then,

$$
\begin{aligned}
& \varepsilon_{q}=2 \gamma_{0}, \\
& \sigma=\frac{E}{4 \gamma_{0}} \cdot \varepsilon^{2}, \quad \varepsilon \leq \varepsilon_{q} .
\end{aligned}
$$

The method of solving the theoretical data on the right side of point $Q$ can be achieved using the above methods. It is noteworthy that, since the numerical value of the $\gamma_{0}$ is determined by a graphical method and the curve segment $O_{1} Q$ is fitted by a quadratic function, there is a certain simplification and estimation intrinsic to the method. Therefore, although point $Q$ is the critical point of the theoretical compaction stage, its identification is prone to error. In practical application, it is found that taking the initial damage point $P$ as the critical point is more accurate and reliable.

\section{Experiment Verification and Analysis}

4.1. Experiment Materials and Methods. In order to verify the model proposed in this paper, a series of consolidated drained triaxial compression tests on cemented sand were performed. The sand used in this test was taken from a beach in Guangdong Province, as shown in Figure 6 [4], with specific gravity $G_{\mathrm{s}}=2.78$. The grain size distribution is shown in Figure 7 . The mean grain size is $D_{50}=0.18 \mathrm{~mm}$, the coefficient of uniformity is $C_{\mathrm{u}}=1.75$, and the coefficient of curvature is $C_{\mathrm{c}}=0.89$. The minimum and maximum dry densities are 1.47 and 1.63 , respectively. The compacted dry density $\rho_{\mathrm{d}}$ was $1.59 \mathrm{~g} / \mathrm{cm}^{3}$. The stabilizer used in this test was Portland cement [26].

The specimens were prepared by mixing sand with $6 \%$ of cement by mass. Then, an appropriate amount of water was added and mixed. Specimens were manually compacted in five layers in a cylindrical mold $(80 \mathrm{~mm}$ in height and $39.1 \mathrm{~mm}$ in diameter) with a controlled compacted layer thickness of $16 \mathrm{~mm}$. The preparation time for each specimen was controlled to under half an hour. Each specimen was cured in the mold for approximately 24 hours and then was removed from the mold and stored in the maintenance room for additional curing. The curing temperature was $22 \pm 2{ }^{\circ} \mathrm{C}$, and the curing period was 28 days.

The specimens were mounted and saturated in the following steps. Firstly, a saturated porous disk was placed on the specimen base after wiping away all free water on the disk. The rubber membrane was placed around the specimen, and it was sealed at the cap and base; the specimens were presaturated in a vacuum cylinder [27]. Ensure that the specimen cap, specimen, and porous disks were centered on the specimen base. Secondly, the axial load piston was brought into contact with the specimen cap, and the specimen was filled with deaired water; a chamber pressure of $35 \mathrm{kPa}$ or less was applied, and the specimen drainage valves were opened. Thirdly, when the pore pressure at the bottom of the specimen stabilized, simultaneously the chamber and back pressure were increased in steps with specimen drainage valves opened so that deaired water from the burette connected to the top and bottom of the specimen may flow into the specimen. The difference between the chamber pressure and the back pressure during back pressuring should not exceed $35 \mathrm{kPa}$. Finally, after closing the specimen drainage valves, the pore pressure was recorded and the chamber pressure was increased. After approximately $2 \mathrm{~min}$, the maximum value of the induced pore pressure was determined and recorded. The pore pressure Parameter $B$ was taken to determine if saturation was completed. Specimens were considered to be saturated if the value of $B$ was equal to or greater than 0.95 or if $B$ remained unchanged with addition of back pressure increments. If $B$ was continuing to increase with increasing back pressure, continue with back pressure saturation. The pore pressure Parameter $B$ is defined by the following equation [28]:

$$
B=\frac{\Delta u}{\Delta \sigma_{3}},
$$

where $\Delta u$ is change in the specimen pore pressure that occurs as a result of a change in the chamber pressure when the specimen drainage valves are closed and $\Delta \sigma_{3}$ is otropic change in the chamber pressure.

When the saturation phase of the test was completed, the axial load piston was brought into contact with the specimen cap and the readings on the deformation indicator were recorded. Then, after closing the specimen drainage valves, the maximum back pressure was held constant and the chamber pressure was increased until the difference between the chamber pressure and the back pressure equaled the desired effective consolidation pressure values, which were $100 \mathrm{kPa}, 200 \mathrm{kPa}, 300 \mathrm{kPa}$, and $400 \mathrm{kPa}$, respectively. The loading rate of confining pressure was $5 \mathrm{kPa} / \mathrm{s}$, and the ambient temperature was $21.5^{\circ} \mathrm{C}$ during the test. The initial reading on the volume change device was recorded, and then, appropriate drainage valves were opened to ensure that the specimen may drain from both ends into the volume change device. The readings on the volume change device were obtained at increasing intervals of elapsed time (0.1, $0.2,0.5,1,2,4,8,15$, and $30 \mathrm{~min}$ and at 1, 2, 4h, and so forth). Specimens were considered to be consolidated if the value of the volume change device was kept stable. During shear, the cell pressure shall be kept constant while advancing the axial load piston downward against the specimen cap using controlled axial deformation as the loading criterion. The axial strain rate was $0.1 \mathrm{~mm} / \mathrm{min}$, and the load cell was external to the cell. Specimen drainage was permitted during shear, and volume changes could be read from the burette [28]. When shear was completed, the axial load was removed and the chamber and back pressures were reduced to zero; 


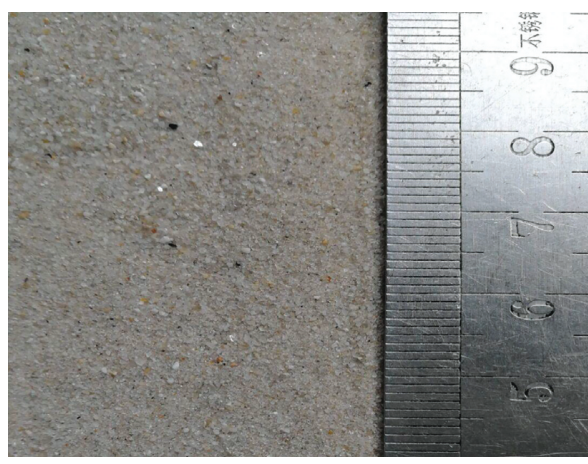

(a)

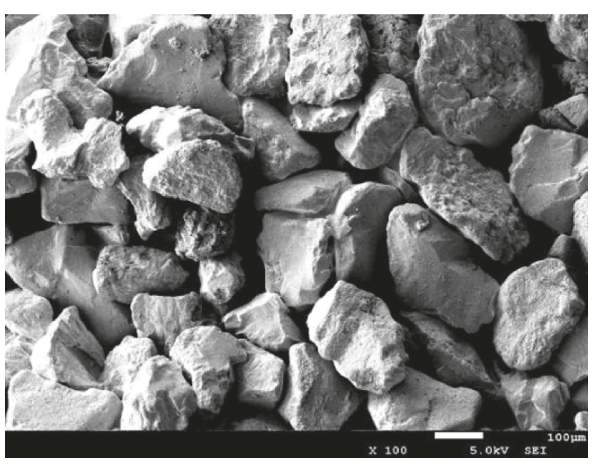

(b)

FIgURE 6: Sand used in the test (reproduced from Tan et al. [4]). (a) Camera figure. (b) SEM figure.

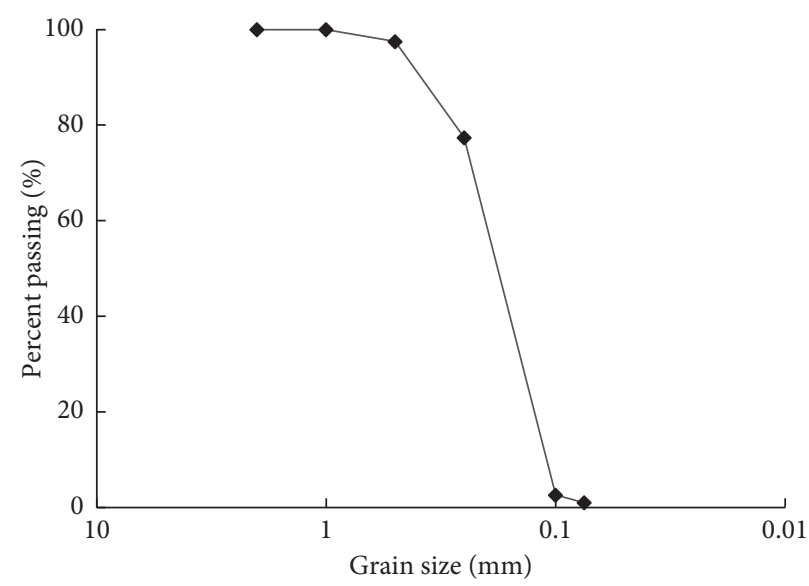

Figure 7: Grain size distribution of sand.

TABLE 1: Model parameters.

\begin{tabular}{lcccccccccc}
\hline$\sigma_{3}(\mathrm{kPa})$ & $m$ & $F_{0}$ & $\gamma_{0}(\%)$ & $\varepsilon_{0}(\%)$ & $C(\mathrm{kPa})$ & $\Phi\left(^{\circ}\right)$ & $\mu$ & $E(\mathrm{MPa})$ & $c_{\mathrm{r}}(\mathrm{kPa})$ & $\varphi_{\mathrm{r}}\left(^{\circ}\right)$ \\
\hline 100 & 1.87 & 1800.5 & 0.33 & 0.53 & 452 & 37.9 & 0.38 & 208 & 219 \\
200 & 1.62 & 1913.3 & 0.24 & 0.48 & 452 & 37.9 & 0.38 & 208 & 219 \\
300 & 1.51 & 2024.8 & 0.18 & 0.42 & 452 & 37.9 & 0.38 & 208 & 219 \\
400 & 1.38 & 2132.6 & 0.13 & 0.39 & 452 & 37.9 & 0.38 & 208 & 219 \\
\hline
\end{tabular}

then the specimen was removed, and the instruments were cleaned up.

4.2. Verification and Analysis. Using the triaxial compression test results, the parameters of the statistical damage constitutive model considering residual strength and initial compaction phase were determined, as shown in Table $1 . m$ and $F_{0}$ can be obtained by Equation (22), the procedure for obtained $\gamma_{0}, \varepsilon_{0}$, and $E$ are listed in Section 3 , and $c, \varphi, c_{\mathrm{r}}$, and $\varphi_{\mathrm{r}}$ were obtained by Mohr-Coulomb strength theory.

The theoretical stress-strain curves under different confining pressures can be obtained from the statistical constitutive model of cemented sand mentioned above and compared with the experimental curves, as shown in
Figure 8. The cemented sand has obvious strain-softening and residual strength characteristics in the triaxial compression condition, and there is obvious nonlinear deformation in the initial compaction stage. The transformed coordinate system can avoid the influence of deformation in the void compaction stage, thus satisfying the assumption that the volume is constant in the model. The theoretical statistical damage constitutive model curve proposed in this paper coincides with the experimental curve well, which verifies the rationality and feasibility of the proposed model.

\section{Conclusion}

A statistical damage constitutive model for cemented sand considering the residual strength and initial compaction phase was proposed in this paper. The model mainly 


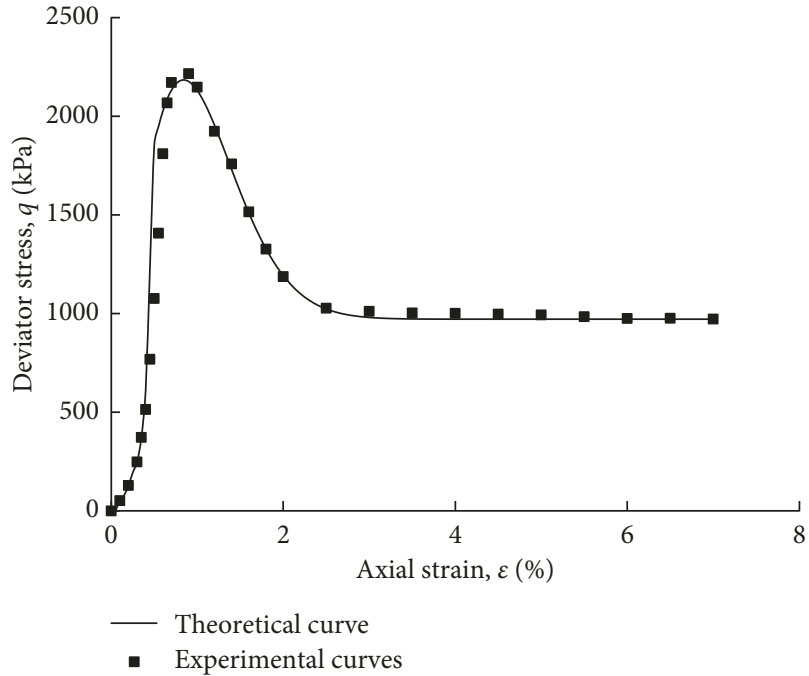

(a)

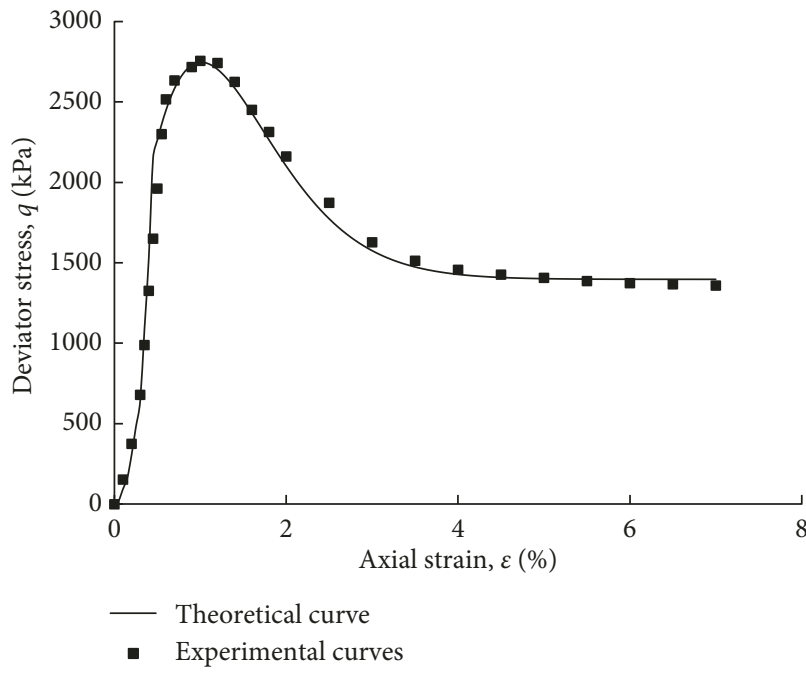

(c)

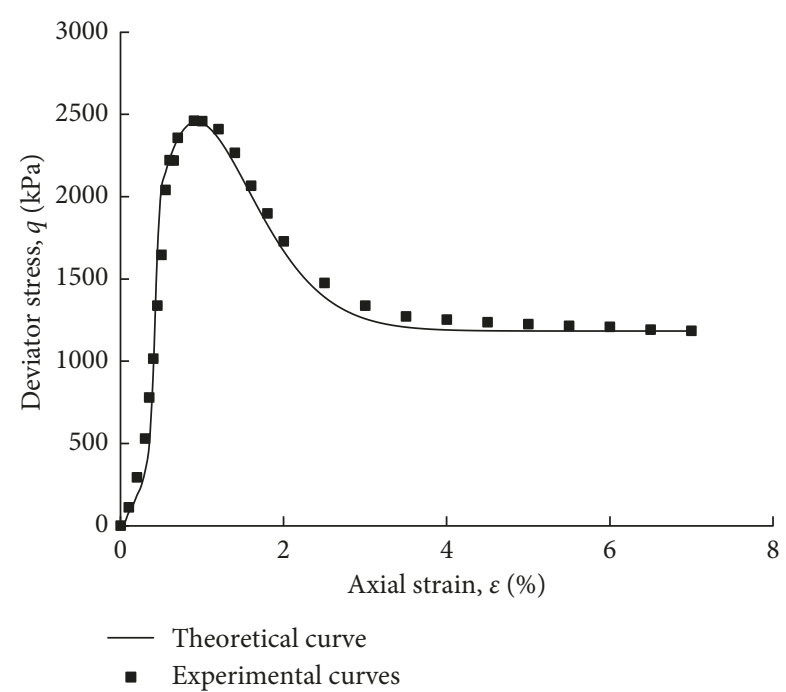

(b)

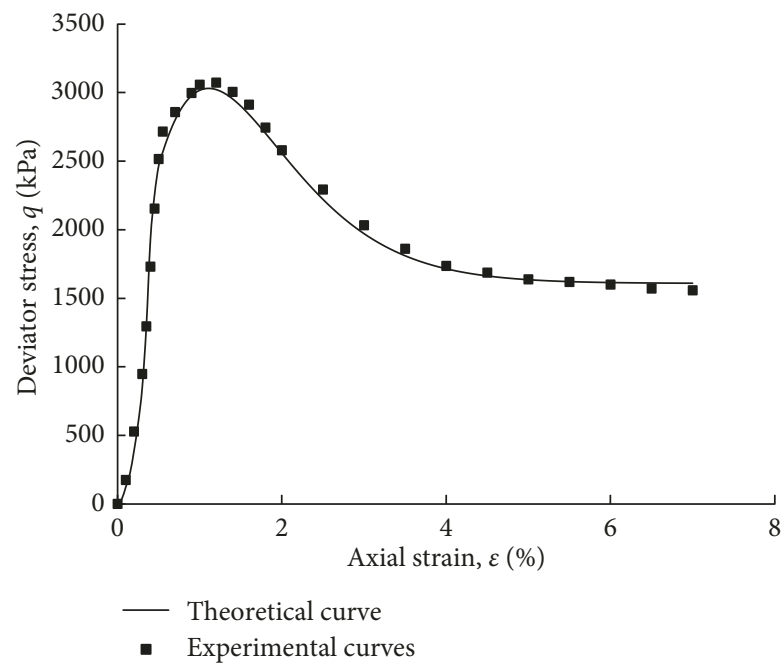

(d)

FigURE 8: Experimental and theoretical curves under different confining pressures. (a) $\sigma_{3}=100 \mathrm{kPa}$. (b) $\sigma_{3}=200 \mathrm{kPa}$. (c) $\sigma_{3}=300 \mathrm{kPa}$. (d) $\sigma_{3}$ $=400 \mathrm{kPa}$.

concerned with deviatoric stress-axial strain relationship. Then, a triaxial compression test was carried out to verify this proposed model. The following conclusions were obtained:

(1) Cemented sand under a triaxial stress condition resulted in complex behavior with characteristics of stress softening, residual strength, and initial compaction. The constitutive model proposed in this paper can reflect the above characteristics well with few parameters.

(2) The deformation of cemented sand was nonlinear in the initial stage. The initial damage point is proposed as the critical point of initial compaction stage, and the initial void compaction stage can be fitted by a quadratic function.

\section{Data Availability}

The data sets generated and analyzed during the current study are not publicly available but are available from the corresponding author on reasonable request.

\section{Conflicts of Interest}

The authors declare that there are no conflicts of interest regarding the publication of this paper.

\section{Acknowledgments}

The authors thank Dr. Wang Chen for the valuable suggestions to the article. This study is funded by the Water 
Resource Science and Technology Innovation Program of Guangdong Province (2014-09).

\section{References}

[1] C. J. Fitzgerald, P. H. Taylor, J. Orszaghova, A. G. L. Borthwick, C. Whittaker, and A. C. Raby, "Irregular wave runup statistics on plane beaches: application of a Boussinesq-type model incorporating a generating-absorbing sponge layer and secondorder wave generation," Coastal Engineering, vol. 114, pp. 309-324, 2016.

[2] B. Zanuttigh, S. M. Formentin, and J. W. V. D. Meer, "Prediction of extreme and tolerable wave overtopping discharges through an advanced neural net work," Ocean Engineering, vol. 127, pp. 7-22, 2016.

[3] M. R. A. V. Gent, H. F. P. V. D. Boogaard, B. Pozueta et al., "Neural network modelling of wave overtopping at coastal structures," Coastal Engineering, vol. 54, pp. 586-593, 2007.

[4] C. Tan, M. D. Yuan, Y. S. Shi et al., "Research on the mechanical properties and damage model of cemented sand under uniaxial compression," IOP Conference Series: Earth and Environmental Science, vol. 170, pp. 1-8, 2018.

[5] M. Obermayr, K. Dressler, C. Vrettos, and P. Eberhard, "A bonded-particle model for cemented sand," Computers and Geotechnics, vol. 49, pp. 299-313, 2013.

[6] A. V. D. Fonseca, S. Rios, M. F. Amaral, and F. Panico, "Fatigue cyclic tests on artificially cemented soil," Geotechnical Testing Journal, vol. 36, no. 2, pp. 1-10, 2013.

[7] S. Rios, A. V. D. Fonseca, and B. A. Baudet, "Effect of the porosity/cement ratio on the compression of cemented soil," Journal of Geotechnical \& Geoenvironmental Engineering, vol. 138, no. 11, pp. 1422-1426, 2012.

[8] N. Trads and P. V. Lade, "Experimental evidence of truly elastic behavior of artificial sandstone inside the cementation yield surface," Rock Mechanics and Rock Engineering, vol. 47, pp. 335-345, 2014.

[9] N. C. Consoli, A. V. Fonseca, S. R. Silva, R. C. Cruz, and A. Fonini, "Parameters controlling stiffness and strength of artificially cemented soils," Géotechnique, vol. 62, no. 2, pp. 177-183, 2015.

[10] N. C. Consoli, R. C. Cruz, and M. F. Floss, "Variables controlling strength of artificially cemented sand: influence of curing time," Journal of Materials in Civil Engineering, vol. 23, no. 5, pp. 692-696, 2011.

[11] N. C. Consoli, A. D. Rosa, M. B. Corte et al., "Porosity-cement ratio controlling strength of artificially cemented clays," Journal of Materials in Civil Engineering, vol. 23, no. 8, pp. 1249-1254, 2011.

[12] X. M. Wang, C. Zhao, S. X. Chen et al., "Experimental study of physico-mechanical properties of artificially cemented sand," Rock and Soil Mechanics, vol. 34, pp. 3134-3140, 2013.

[13] E. Ravanbakhsh and A. Hamidi, "Development of a generalized plasticity constitutive model for cemented sands using critical state concepts," International Journal of Geotechnical Engineeringineering, vol. 7, no. 4, pp. 364-373, 2013.

[14] K. R. Reddy and S. K. Saxena, "Constitutive modeling of cemented sand," Mechanics of Materials, vol. 14, no. 2, pp. 155-178, 1992.

[15] Z. Gao and J. Zhao, "Constitutive modeling of artificially cemented sand by considering fabric anisotropy," Computers and Geotechnics, vol. 41, pp. 57-69, 2012.

[16] S. Li, Y. Lai, S. Zhang, and D. Liu, "An improved statistical damage constitutive model for warm frozen clay based on
Mohr-Coulomb criterion," Cold Regions Science and Technology, vol. 57, pp. 154-159, 2009.

[17] J. Deng and D. Gu, "On a statistical damage constitutive model for rock materials," Computers and Geosciences, vol. 37, pp. 122-128, 2011.

[18] Z. L. Wang, Y. C. Li, and J. G. Wang, "A damage-softening statistical constitutive model considering rock residual strength," Computers and Geosciences, vol. 33, pp. 1-9, 2007.

[19] J. B. Wang, Z. P. Song, B. Y. Zhao et al., "A study on the mechanical behavior and statistical damage constitutive model of sandstone," Arabian Journal for Science and Engineering, vol. 4, pp. 1-14, 2017.

[20] W. G. Cao, H. Zhao, X. Li et al., "A statistical damage simulation method for rock full deformation process with consideration of the deformation characteristics of residual strength phase," China Civil Engineering Journal, vol. 45, pp. 139-145, 2012.

[21] A. Lionco and A. Assis, "Behaviour of deep shafts in rock considering nonlinear elastic models," Tunnelling and Underground Space Technology Incorporating Trenchless Technology Research, vol. 15, pp. 445-451, 2000.

[22] Q. Y. Wang, W. C. Zhu, T. Xu, H. L. Liu, and J. G. Jia, "Numerical analysis on nonlinear deformation behavior of rock considering compaction of pores," Scientia Sinica Technologica, vol. 48, no. 5, pp. 565-574, 2018.

[23] W. G. Cao, C. Zhang, M. He et al., "Statistical damage simulation method of strain softening deformation process for rocks considering characteristics of void compaction stage," Chinese Journal of Geotechnical Engineering, vol. 38, pp. 1754-1761, 2016.

[24] J. Lemaitre, "A continuous damage mechanics model for ductile fracture," Journal of Engineering Materials and Technology, vol. 107, no. 1, pp. 83-89, 1985.

[25] P. B. Arthur, P. C. Ken, and D. L. James, Elasticity in Engineering Mechanics, John Wiley \& Sons, Inc., New Jersey, Canada, 2011.

[26] C. Wang and W. Li, "Factors affecting the mechanical properties of cement-mixed gravel," Advances in Materials Science and Engineering, vol. 2016, Article ID 8760325, 7 pages, 2016.

[27] Trade Standard of P.R. China, SL237-1999 Specification of Soil Test, Ministry of Water Resources of P. R. China, Beijing, China, 1999.

[28] ASTM committee on standards, D2850-03a, Standardtest Method for Consolidated Drained Triaxial Compression Test for Cohesive Soils, ASTM International, West Conshohocken, PA, USA, 2003. 


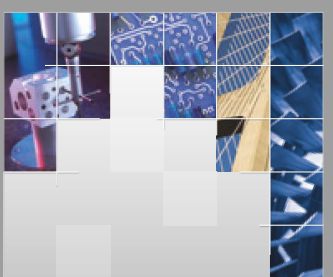

\section{Enfincering}
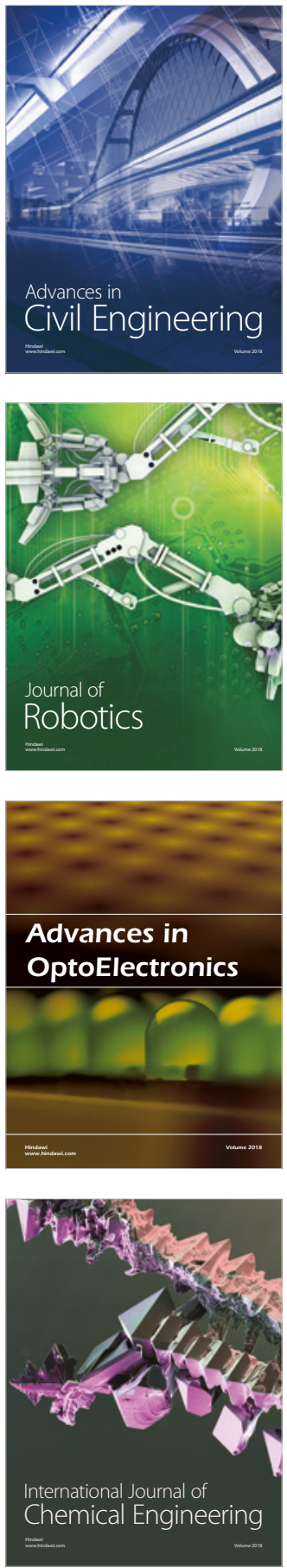

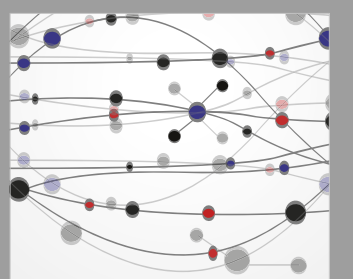

\section{Rotating \\ Machinery}

The Scientific World Journal

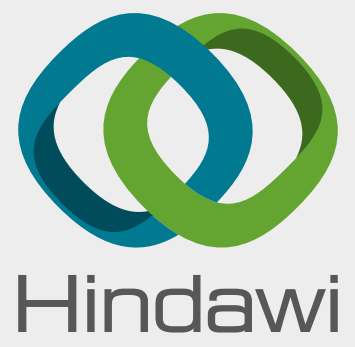

Submit your manuscripts at

www.hindawi.com
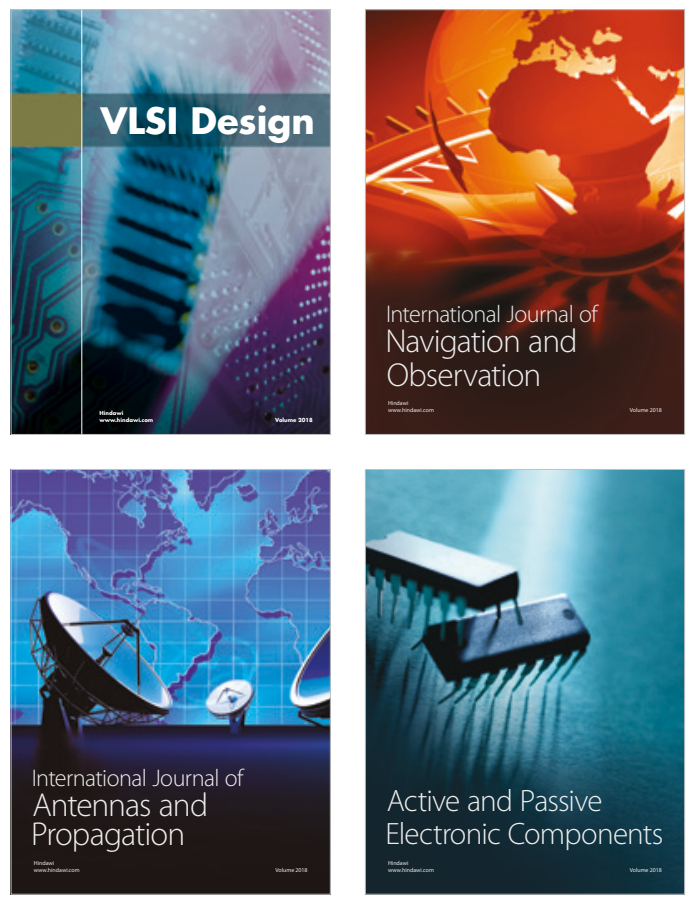
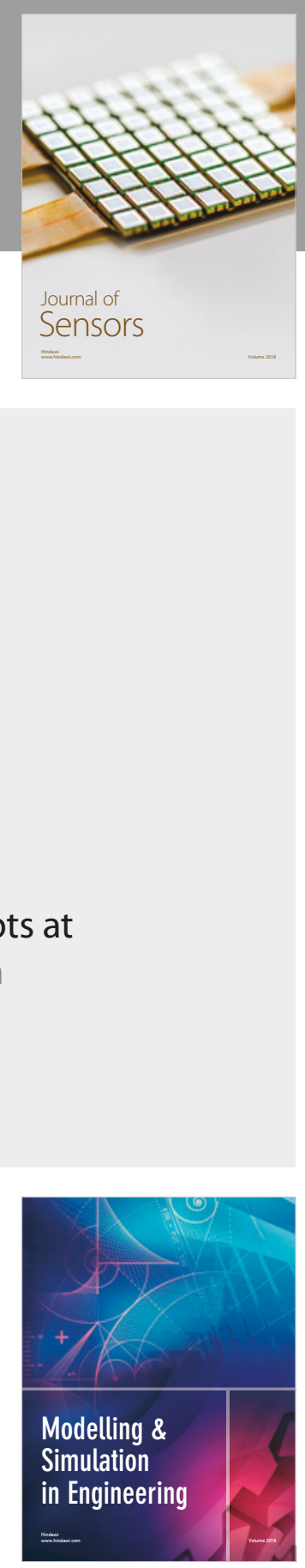

\section{Advances \\ Multimedia}
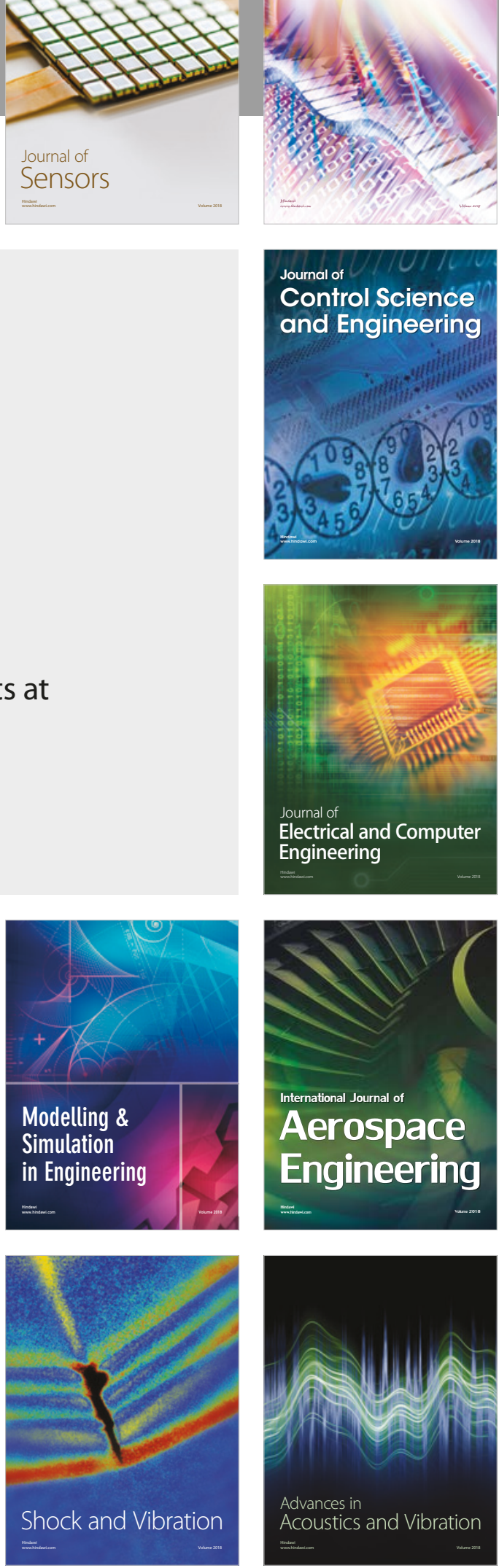